\title{
Antecedents of Opportunity at Work: Evidence from White-Collar Employees in Turkey
}

\author{
Elif Çiçeklia
}

\author{
Hayat Kabasakal $^{\mathrm{b}}$
}

\begin{abstract}
Opportunities provided to employees at work facilitate important organizational outcomes. Although opportunity at work is a significant topic of research, antecedents of opportunity are under-explored. The study aims to analyze the relationships between opportunity at work and possible antecedents of opportunity, i.e. different types of leadership and high performance work practices. For this purpose, factor analyses and hierarchical multiple regression analyses are carried out using data from 550 white-collar employees. The results of analyses show that opportunity at work is explained with reference to three factors: Promotion, development, and recognition opportunities. Transactional, transformational, and participative leadership create at least one type of opportunity for employees. High performance work practices (HPWPs) predict development and promotion opportunity for employees working in different industries. The study fills a gap in the literature by exploring antecedents of opportunity at work, with important implications for both research and practice. Managers are advised to adopt the characteristics of transactional, transformational, and participative leadership in order to create opportunities for their subordinates. Moreover, organizations are recommended to employ HPWPs to create opportunities for their employees.
\end{abstract}

Keywords: Promotion Opportunity, Development Opportunity, Recognition Opportunity, High Performance Work Practices, Leadership

JEL Classification: M51, M53, M54

\section{Introduction}

Opportunity provided to employees at work include promotion opportunity, development opportunity, challenge (Kanter, 1977; Kanter \& Stein, 1981), and recognition opportunity (Kanter, 1986; Wayne et al., 2002). Opportunity at work has been shown to be related to many important organizational outcomes, such as organizational commitment (Chew \& Chan, 2008; Ganesan \& Weitz, 1996; Landau \& Hammer, 1986), job satisfaction (Appelbaum \& Kamal, 2000) job performance (Allen et al., 1998), and organizational performance (Birdi et al., 2012) which shows that opportunity is significant for both employees and employers.

In addition, opportunity at work is a positive phenomenon in itself. The Positive Organizational Scholarship (POS) approach emphasizes the enablers, the motivations, and the outcomes or effects of positive phenomena in organizations (Cameron et al., 2003). Likewise, in this study, the enablers of a positive phenomenon, i.e. opportunity, are examined. POS puts emphasis on positive organizational outcomes not 
only as means but also ends, which are believed to be worth explaining on their own (Dutton et al., 2006). Thus, although opportunity at work is significant as an enabler of important organizational outcomes, it is worth explaining on its own as well, since it is valuable in and of itself. Hence, antecedents of opportunity at work are of paramount importance.

Although opportunity is a significant topic of research, its antecedents have been under-explored. The antecedents of opportunity that have been studied in previous research include socioeconomic status (Colarelli et al., 1987), employee tenure and demographic variables such as age (Landau \& Hammer, 1986), gender (Cassirer \& Reskin, 2000; Igbaria \& Baroudi, 1995), and education (Tachibanaki, 1987; Zhao et al., 2006). However, more research is needed to cover all possible antecedents of opportunity. This study fills a gap in the literature by exploring antecedents of opportunity at work, with important implications for both research and practice. The study focuses on high performance work practices and leadership types as antecedents of opportunity at work.

\section{Literature Review and Hypotheses}

\subsection{Opportunity at Work}

Some researchers have restricted the definition of opportunity to promotion opportunities. For instance, Harlan (1989:766) defined opportunity in terms of "position in the organizational hierarchy and as workers' perceptions of the degree to which the firm's administrative system awards promotions through fair and open competition". Likewise, Baron et al. (1986) studied opportunity structures in organizations in relation to promotion ladders, and Mano-Negrin and Tzafrir (2004) related opportunity in an organization to the employees' perceptions regarding the degree of internal recruitment for departmental and organizational positions.

Kanter's (1977: 161) description of opportunity as "the relationship of a present position to a larger structure and to anticipated future positions" was balanced by her emphasis on the importance of growth through a job as a type of opportunity at work. Thus, her definition is not restricted to promotion, but covers "movement from" or "growth through" a specific job ( $\mathrm{p:161)}$ arguing that the structure of opportunity in a job is determined by matters such as promotion rates, access to challenge, and skill increases. Similarly, Kanter and Stein (1981) argue that opportunity includes not just promotion but also other types of opportunity, such as the development of professional skills and continual challenge. Parallel to these arguments, some scholars have argued that the concept of opportunity at work should not be confined to promotion opportunity, since opportunities for upward mobility in the workplace have been reduced in recent years. For instance, lles (1997: 352) explained that opportunities for upward mobility have been reduced due to organizational restructuring, downsizing, outsourcing and delayering; he proposed that since "organizations still need to recruit, retain and motivate people with the potential to lead the organization", fast-track programmes for high-potential employees should be re-evaluated. Feldman (1996) argued that organizations need to shift their focus from opportunities for advancement to opportunities for growth and development, because of the trend regarding downsizing and layoffs. Similarly, although they only studied the promotion aspect of opportunity, Yang et al. (2004) recommended that scholars examine how employees value other dimensions of opportunity, such as opportunities to accumulate work experiences and to develop skills.

Some scholars have mentioned challenge-that is, the opportunity for challenging work, lateral moves with new challenges, and new responsibilities (Caudron, 1994; Kanter \& Stein, 1981)-as an opportunity at work. Caudron (1994: 64) discussed that, rather than only encouraging promotions, companies could provide opportunities for lateral growth, enriched jobs, and "dual career paths, in which employees are given additional challenges and compensation without having to advance into managerial positions".

Recognition is another type of opportunity mentioned by researchers. Kanter (1986) emphasized the significance of recognition and discussed the idea that accessibility to rewards and recognition is a necessity, 
because companies cannot afford promotion as the primary means of recognizing performance due to shrinking corporate hierarchies and the removal of organizational layers. Wayne et al. (2002) claimed that recognition and visibility are likely to be given to a small group of employees and imply a bright future. Hence, recognition is a type of opportunity as well.

In sum, the types of opportunity covered in the literature include:

- Promotion opportunity (Caudron, 1994; Harlan, 1989; Kanter, 1977; Kanter \& Stein, 1981),

- Development opportunity (Feldman, 1996; lles, 1997; Kanter, 1977; Kanter \& Stein, 1981; Yang et al., 2004),

- Continual challenge (i.e., opportunity for challenging work, new responsibilities, and lateral moves with new challenges) (Caudron, 1994; Kanter, 1977; Kanter \& Stein, 1981), and

- Recognition opportunity (Kanter, 1986; Wayne et al., 2002).

This study utilizes a broad definition of opportunity, which includes all of the above as dimensions of opportunity as perceived by employees.

\subsection{High Performance Work Practices and Opportunity at Work}

High performance work practices (HPWPs) are human resource practices that have consistently been empirically proven to enhance firm performance (Huselid, 1995). These practices include "extensive recruitment, selection, and training procedures" as well as "performance appraisal, promotion, and incentive compensation systems that recognize and reward employee merit" (Huselid, 1995: 640), treating employees as permanent members of staff, hiring new employees with care, promoting from within the company, supporting growth and development, and providing training (Taylor et al., 2008). HPWPs have been studied under different names such as high commitment human resource practices (Arthur, 1992).

There are many studies on the relationship between HPWPs and different organizational outcomes. Previous studies have shown that HPWPs are related to employee commitment (Taylor et al., 2008), employee turnover, employee productivity (Huselid, 1995), and firm performance (Combs et al., 2006; Huselid, 1995). However, the effect of HPWPs on the opportunity perceptions of employees is underresearched. Since HPWPs involve promoting from within the company (Taylor et al., 2008) and promotion "systems that recognize and reward employee merit" (Huselid, 1995: 640), it is hypothesized that HPWPs influence the promotion opportunity perceptions of employees in a positive way. Furthermore, since HPWPs involve extensive training procedures (Huselid, 1995) and support for growth and development (Taylor et al., 2008), it is hypothesized that HPWPs also influence the development opportunity perceptions of employees in a positive way. Moreover, since HPWPs involve the opportunity to use the skills one has, and since workers may find working in HPWPs more challenging than working in a traditional work system (Appelbaum et al., 2000), it is hypothesized that HPWPs increase the challenge employees experience. Finally, since HPWPs involve HR practices such as employee involvement and participation (Arthur, 1992), it is hypothesized that HPWPs enable employees to perceive themselves as visible and recognized. Thus, the following hypotheses are proposed:

Hypothesis 1a: HPWPs are positively related to promotion opportunity.

Hypothesis 1b: HPWPs are positively related to development opportunity.

Hypothesis 1c HPWPs are positively related to continual challenge.

Hypothesis 1d: HPWPs are positively related to recognition opportunity.

\subsection{Leadership and Opportunity at Work}

It is estimated that different types of leadership are related to different types of opportunity at work. Four types of leadership are studied. Two of them (i.e. transactional and transformational leadership) are 
from the leadership categorization by Avolio and Bass (2001) who found that the most effective leaders are not only transactional but also transformational. They state that both transactional and transformational leaders can be either democratic and participative or directive, decisive, and authoritative. Since participative leadership has been shown to be beneficial in improving opportunity related issues at work (House, 1996; Huang et al., 2006; Yukl, 2002), it is included in this study as well. Since the study is carried out in Turkey, and paternalistic leadership is very prominent in Turkish culture (Aycan, 2001; Dilber, 1967; Kabasakal \& Bodur, 2002), paternalistic leadership is included in the study as well. Thus, the types of leadership studied are paternalistic, transactional, transformational, and participative leadership.

\subsubsection{Paternalistic Leadership}

The term "paternalistic relationship" arises from the style of leadership that is considered to resemble the relationship between a father or a parent and a child (Aycan, 2001; Fikret-Pasa et al., 2001; Fleming, 2005). The authority figure in the paternal relationship has been described as "analogous to a father who does not forcibly control or direct the activities of his child or children but guides them in an understanding and loving way" (Lee, 2001: 841).

In paternalistic human resource management (HRM), the paternal figure (employer or manager) considers employees and takes the employees' rights and feelings into account, while providing support and protection to those under his or her care. In return for this support and protection, subordinates show loyalty, deference, compliance, and cooperation (Aycan, 2001; Lee, 2001). More specifically, paternal figures act like parents, care about employees' private problems, and 'take a personal interest in workers' off-the-job lives and personal problems and attempt to promote workers' personal welfare and help them achieve personal goals" (Fikret-Pasa et al., 2001: 561).

Lee (2001) studied paternalistic HR practices in Korea and argued that paternalistic HRM lacks rationality, since it depends on non-institutional and informal personal ties and there is managerial autonomy with respect to hiring, staffing, and training, which may imply that paternalism is negatively related to the opportunity perceptions of employees. However, this style is perceived more positively in paternalistic cultures like Turkey (Aycan, 2001; Dilber, 1967; Kabasakal \& Bodur, 2002), and it has positive many effects as well. Since paternal leaders provide support and protection to those under their care (Aycan, 2001; Lee, 2001), "attempt to promote workers' personal welfare and help them achieve personal goals" (Fikret-Pasa et al., 2001: 561), and focus on their subordinates' overall welfare, in both off-the-job and work domains (Pellegrini et al., 2010), it is estimated that employees will perceive there to be greater opportunities for promotion, development, continual challenge, and recognition. Thus, it is hypothesized that:

Hypothesis 2a: Paternalistic leadership is positively related to promotion opportunity.

Hypothesis $2 \mathrm{~b}$ : Paternalistic leadership is positively related to development opportunity.

Hypothesis 2c: Paternalistic leadership is positively related to continual challenge.

Hypothesis 2d: Paternalistic leadership is positively related to recognition opportunity.

\subsubsection{Transactional Leadership}

Transactional leadership is related "to the exchange relationship between leader and follower to meet their own self-interests" (Bass, 1999: 10). Transactional leadership involves dimensions of contingent rewarding and management-by-exception. Contingent rewarding involves "defining the exchanges between what is expected from the follower and what the follower will receive in return" (Rowold \& Heinitz, 2007: 123) and is rooted in Path-Goal Theory, which emphasizes the importance of clearing paths to rewards for employees, as well as contingent rewarding by leaders (House \& Mitchell, 1974).

Previous research has shown that transactional leadership predicts different organizational outcomes, such as employees' organizational commitment (Ali, Babar, \& Bangash, 2011), organizational citizenship behaviour (Eliyana, 2010), and organizational performance (Obiwuru et al., 2011). However, the relationship between transactional leadership and the opportunity perceptions of employees is under- 
researched. Since contingent rewarding in transactional leadership basically involves rewarding employees in exchange for achievements and the attainment of goals, it can be expected that transactional leadership would be related to providing promotion opportunities at work. Since, in contingent rewarding, the leaders make it clear to their followers what they need to do to be rewarded for their efforts (Bass, 1999), it is hypothesized that transactional leadership will also result in more development opportunity, as perceived by employees. Moreover, since in contingent rewarding, the reward is contingent on the level of effort expended and performance achieved (Hartog et al., 1997), it is hypothesized that transactional leadership increases the challenge employees experience. Furthermore, since employees are rewarded for their achievements in contingent rewarding (Avolio et al., 1999), it is hypothesized that employees who experience transactional leadership will feel more visible and recognized. These expectations can be summarized as the following hypotheses:

Hypothesis 3a: Transactional leadership is positively related to promotion opportunity.

Hypothesis 3b: Transactional leadership is positively related to development opportunity.

Hypothesis 3c: Transactional leadership is positively related to continual challenge.

Hypothesis 3d: Transactional leadership is positively related to recognition opportunity.

\subsubsection{Transformational Leadership}

Transformational leader moves "the follower beyond immediate self-interests" (Bass, 1999: 11). Transformational leadership involves four dimensions: inspirational motivation, idealized influence of the leader on the follower, intellectual stimulation, and individualized consideration (Rowold \& Heinitz, 2007). Individualized consideration "refers to leader behaviours aimed at recognizing the unique growth and developmental needs of followers as well as coaching followers and consulting with them" (Bono \& Judge, 2004: 901-902). It involves understanding individual followers' needs and abilities, developing and empowering them (Rowold \& Heinitz, 2007), and working continuously to get the followers to develop to their full potential (Avolio et al., 1999).

Transformational leadership has been shown to be related to different organizational outcomes such as employee empowerment (Ismail et al., 2011), organizational commitment (Ali et al., 2011), organizational citizenship behaviour (Eliyana, 2010), and employee performance (Howell \& Hall-Merenda, 1999). However, the relationship between transformational leadership and the opportunity perceptions of employees is under-researched. Since Rafferty and Griffin (2006: 43) found that two dimensions of individualized consideration (i.e. developmental leadership and supportive leadership) had a positive relationship with career certainty, which is "the extent to which individuals feel that they are provided with opportunities for career advancement, and the extent to which they feel that their job and career are secure", it is hypothesized that transformational leadership influences the promotion opportunity perceptions of employees in a positive way. In addition, since individualized consideration involves recognizing the growth and development needs of employees (Bono \& Judge, 2004) and developing them (Rowold \& Heinitz, 2007) to their full potential (Avolio et al., 1999), it is hypothesized that transformational leadership influences the development opportunity perceptions of employees in a positive way. Moreover, since a "transformational leader may reveal the individualized consideration to convert crises into developmental challenges" (Bass, 1992: 143), it is hypothesized that transformational leadership increases the challenge employees experience. Further, since individualized consideration involves consulting with followers (Bono \& Judge, 2004), and understanding their needs and abilities so as to develop and empower them individually (Rowold \& Heinitz, 2007), it is hypothesized that employees who experience transformational leadership will feel more visible and recognized. Therefore, it is proposed that:

Hypothesis 4a: Transformational leadership is positively related to promotion opportunity.

Hypothesis 4b: Transformational leadership is positively related to development opportunity.

Hypothesis 4c: Transformational leadership is positively related to continual challenge.

Hypothesis 4d: Transformational leadership is positively related to recognition opportunity. 


\subsubsection{Participative Leadership}

In participative leadership, the leader makes efforts to encourage and facilitate participation by employees with respect to making important decisions (Yukl, 2002), so that the leader and subordinate employees share influence in decision making (Huang et al., 2006).

Participative leadership has been shown to be related to different organizational outcomes such as job satisfaction (Gharibvand, 2012), organizational commitment (Huang, 2011), and job performance (Somech \& Wenderow, 2006). However, the relationship between participative leadership and the opportunity perceptions of employees is under-researched. Since the potential benefits of participative leadership include the development of decision-making skills (Yukl, 2002), it is hypothesized that participative leadership influences the development opportunity perceptions of employees in a positive way. Moreover, since participative leadership has been argued to increase employees' effort and performance and the level of pressure for organizational performance (House, 1996), it is hypothesized that participative leadership increases the challenge employees experience. In addition, since leaders and subordinates share decisionmaking influence in participative leadership (Huang et al., 2006), it is hypothesized that employees who experience participative leadership will feel more visible and recognized. This can be set forth as:

Hypothesis 5a: Participative leadership is positively related to development opportunity.

Hypothesis 5b: Participative leadership is positively related to continual challenge.

Hypothesis 5c: Participative leadership is positively related to recognition opportunity.

\subsection{The Hypotheses of the Study}

All of the hypotheses of the study are shown in Table 1.

Table 1. The Hypotheses

\begin{tabular}{ll}
\hline \hline Hypothesis 1a & HPWPs are positively related to promotion opportunity. \\
Hypothesis 1b & HPWPs are positively related to development opportunity. \\
Hypothesis 1c & HPWPs are positively related to continual challenge. \\
Hypothesis 1d & HPWPs are positively related to recognition opportunity. \\
\hline Hypothesis 2a & Paternalistic leadership is positively related to promotion opportunity. \\
Hypothesis 2b & Paternalistic leadership is positively related to development opportunity. \\
Hypothesis 2c & Paternalistic leadership is positively related to continual challenge. \\
Hypothesis 2d & Paternalistic leadership is positively related to recognition opportunity. \\
\hline Hypothesis 3a & Transactional leadership is positively related to promotion opportunity. \\
Hypothesis 3b & Transactional leadership is positively related to development opportunity. \\
Hypothesis 3c & Transactional leadership is positively related to continual challenge. \\
Hypothesis 3d & Transactional leadership is positively related to recognition opportunity. \\
\hline Hypothesis 4a & Transformational leadership is positively related to promotion opportunity. \\
Hypothesis 4b & Transformational leadership is positively related to development opportunity. \\
Hypothesis 4c & Transformational leadership is positively related to continual challenge. \\
Hypothesis 4d & Transformational leadership is positively related to recognition opportunity. \\
\hline Hypothesis 5a & Participative leadership is positively related to development opportunity. \\
Hypothesis 5b & Participative leadership is positively related to continual challenge. \\
Hypothesis 5c & Participative leadership is positively related to recognition opportunity. \\
\hline \hline
\end{tabular}




\section{Method}

\subsection{Sample and Procedure}

The respondents included both managers and non-manager white-collar employees working in manufacturing and service companies of varying sizes in Turkey. A questionnaire was created and pre-tested with a sample of ten white-collar employees (five females and five males) from several companies. The respondents filled in the questionnaire and noted any questions that were unclear. Based on the feedback from the respondents, many items on the questionnaire were clarified. A pilot study was carried out using convenience sampling. The pilot study, in which 102 white-collar employees (56\% women and $28 \%$ managers) from three companies (one in manufacturing, one in retailing, and one in architecture) participated, resulted in further clarification of the questions. The data from the pre-test and the pilot study were not used to test the hypotheses.

Convenience sampling of organizations was used for the actual sample as well. The CEOs or top managers were briefed about the purpose of the study and were promised an executive summary of the findings. After acquiring the management's cooperation in these organizations, the snowballing technique was used to connect with additional CEOs or top managers through referrals. The questionnaires were distributed to employees in person. The employees were briefed about the study and were guaranteed anonymity. In addition to the convenience sampling method, the judgmental sampling method was used: a balanced distribution of males and females, and managers versus non-managers was sought. In order to increase the response rate, the completed questionnaires were collected later during the same day that they were distributed, and the companies were visited several times to remind employees to fill out the questionnaires.

The combination of obtaining permission and cooperation from the CEOs or top management, visiting the companies several times, and requesting employees face-to-face to complete the questionnaires all contributed to a high response rate. Out of 586 white-collar employees contacted, 550 completed the questionnaire, resulting in a response rate of $94 \%$. The respondents were from 75 companies, of which $76 \%$ were in the manufacturing sector, $19 \%$ were in the service sector, $4 \%$ were in the export-import sector, and $1 \%$ were in the retail sector. The respondents were $64 \%$ male; $75 \%$ non-manager. Majority were between the ages of 25 and $39(68 \%)$ and were high school graduates (55\%). Twenty percent had bachelor's degrees and $46 \%$ had tenures of between 6 and 14 years.

The data were collected using self-reported surveys; thus, there was a potential for common method bias (Podsakoff et al., 2003). One potential cause of common method bias is item ambiguity, in which respondents answer ambiguous questions randomly or systematically using their own heuristic (Podsakoff et al., 2003). To avoid item ambiguity, the questionnaire was pretested with a sample of ten white-collar employees and then a pilot study using a sample of 102 white-collar employees. Another potential cause of common method bias is priming effects (Podsakoff \& Organ, 1986), wherein researchers cause respondents to concentrate on certain features of the situation and, as a result, affect their responses (Salancik \& Pfeffer, 1978), since positioning of a "variable on the questionnaire can make that variable more salient to the respondent and imply a causal relationship with other variables" (Podsakoff et al., 2003: 882). To avoid priming effects, the items on dependent variables were placed before the independent variables in the questionnaire, based on the arguments set forth by Salancik and Pfeffer $(1977,1978)$. Moreover, Harman's single-factor test was carried out using the procedure suggested by Podsakoff et al. (2003). The factor analysis produced five factors, rather than a single factor, accounting for $72 \%$ of the variance, and the first factor accounted for $35 \%$ of the total, rather than the majority of the covariance among the measures, thus passing the Harman's test.

\subsection{Measures}

Except for two items which are used to measure development opportunity, all the items used in this study are based on items that have been used in previous research. Instead of using the existing scales in 
their entirety, items from different scales have been adapted and used, since the aim was to form scales that measured as many different dimensions of the variables as possible, using a variety of viewpoints of different scholars. Items on dependent and independent variables are provided in the Appendix.

\subsubsection{Dependent Variables}

Opportunity at work is operationalized using four dimensions, as perceived by employees in their current companies: promotion opportunity, development opportunity, continual challenge, and recognition opportunity.

Promotion opportunity is measured using three items: one adapted from Ganesan and Weitz (1996), one from Greenhaus et al. (1990) and Igbaria and Baroudi (1995), and another from Kalleberg and Van Buren (1996).

Development opportunity is measured using three items. One item is adapted from Kim et al. (1996), one from Prince (2005), and one from Noe et al. (1988).

Continual challenge is measured with three items: The single item that measures job challenge is adapted from Carmeli (2005). To measure the level of opportunity for lateral moves with new challenges, a new item was produced: "In my present company, I have the chance to do a different job or work in a different department in which I can learn new things" since there were no previously developed scales to measure it. Similarly, opportunity for new responsibilities was measured with a newly produced item: "My job may get bigger through new responsibilities in the future."

Recognition opportunity is operationalized using three items adapted from Wayne et al. (2002).

\subsubsection{Independent Variables}

Following Taylor et al. (2008), HPWPs were considered as a one-factor variable instead of separate activities. HPWPs are measured using four items from the scale compiled by Taylor et al. (2008), who utilized certain scales previously developed by various researchers, including Huselid (1995) and Delery and Doty (1996).

For leadership, the respondents were asked to evaluate their immediate managers in terms of different leadership attributes on a scale of 1 (strongly disagree) to 5 (strongly agree).

Paternalistic leadership is measured using three items adapted from the 21-item scale used by Aycan (2006).

One dimension of transactional leadership, namely contingent rewarding, is used. Contingent rewarding was measured using a total of three items, two of which were adapted from Avolio et al. (1999). One item set forth by Greenhaus et al. (1990: 85) to measure supervisory support ("My supervisor makes sure I get the credit when I accomplish something substantial on the job") is adapted and used as well, since it is very much related to contingent rewarding.

One dimension of transformational leadership, namely individualized consideration, is used. Individualized consideration is measured using a total of three items, two of which were adapted from Rafferty and Griffin (2006). Another item is produced using the operational definition of individualized consideration posited by Avolio et al. (1999: 444): "Individualized Consideration focuses on understanding the needs of each follower and works continuously to get them to develop to their full potential"; which is adapted as "My manager works to get me to develop to my full potential".

For participative leadership, following Huang et al. (2006), three items from the scale of Empowering Leadership Questionnaire by Arnold et al. (2000) are adapted and used to measure participative leadership behaviour. 


\subsubsection{Control Variables}

In terms of control variables, previous research has shown that age (Landau \& Hammer, 1986) and employee tenure (Kalleberg \& Van Buren, 1996; Landau \& Hammer, 1986) are negatively related to perceived ease of movement. In terms of gender, women are perceived to have less favourable chances of promotion than men (Igbaria \& Baroudi, 1995), while men have a more favourable location in opportunity structures (Cassirer \& Reskin, 2000). Junior college and university graduates have much more chance of being promoted than either junior or senior high school graduates (Tachibanaki, 1987), and MBA education has a positive impact on job promotion (Zhao et al., 2006). Previous research has also shown that the variable socioeconomic status accounts for the most variance in promotability (Colarelli et al., 1987). Based on the results of these studies, age, tenure, gender, education, and socioeconomic status were used as control variables.

\section{Results}

\subsection{Summary Statistics of Variables Studied}

Table 2 shows the means, the standard deviations, and the coefficients of correlation and reliability of the uncentred study variables.

Table 2. Descriptive Statistics and Correlations

\begin{tabular}{|c|c|c|c|c|c|c|c|c|c|c|c|}
\hline \multicolumn{2}{|c|}{ Variable } & \multirow{2}{*}{$\begin{array}{r}M \\
2.49\end{array}$} & \multirow{2}{*}{$\begin{array}{l}\text { SD } \\
.91\end{array}$} & \multirow{2}{*}{$\begin{array}{l}1 \\
(.84)\end{array}$} & \multirow[t]{2}{*}{2} & \multirow[t]{2}{*}{3} & \multirow[t]{2}{*}{4} & \multirow[t]{2}{*}{5} & \multirow[t]{2}{*}{6} & \multirow[t]{2}{*}{7} & \multirow[t]{2}{*}{8} \\
\hline 1 & $\begin{array}{l}\text { Promotion } \\
\text { opportunity }\end{array}$ & & & & & & & & & & \\
\hline 2 & $\begin{array}{l}\text { Development } \\
\text { opportunity }\end{array}$ & 3.33 & .80 & .04 & $(.88)$ & & & & & & \\
\hline 3 & $\begin{array}{l}\text { Recognition } \\
\text { opportunity }\end{array}$ & 3.05 & .87 & .02 & $-.00^{a}$ & (.91) & & & & & \\
\hline 4 & HPWPs & 3.40 & .71 & $.20 * *$ & $.48^{* *}$ & $.24^{* *}$ & (.74) & & & & \\
\hline 5 & $\begin{array}{l}\text { Paternalistic } \\
\text { leadership }\end{array}$ & 3.67 & .78 & -.08 & $.19 * *$ & $.10^{*}$ & $.43^{* *}$ & (.78) & & & \\
\hline 6 & $\begin{array}{l}\text { Transactional } \\
\text { leadership }\end{array}$ & 3.31 & .84 & $.21 * *$ & $.19 * *$ & .07 & $.30 * *$ & .00 & $(.87)$ & & \\
\hline 7 & $\begin{array}{l}\text { Transformational } \\
\text { leadership }\end{array}$ & 3.50 & .84 & .08 & $.30 * *$ & .06 & $.24 * *$ & -.01 & .02 & (.90) & \\
\hline 8 & $\begin{array}{l}\text { Participative } \\
\text { leadership }\end{array}$ & 3.43 & .92 & $.16^{* *}$ & $.43^{* *}$ & $.24^{* *}$ & $.37 * *$ & -.01 & -.01 & .01 & $(.92)$ \\
\hline
\end{tabular}

Note. Cronbach's alpha coefficients are in parentheses on the diagonal.

${ }^{a}$ The value shown as .00 is less than .005 .

${ }^{*} \mathrm{p}<.05$, two-tailed, ${ }^{* *} \mathrm{p}<.01$, two-tailed.

Although factor scores of HPWPs and leadership dimensions were calculated and used in the regression analyses, all variables' sum scores are reported in Table 2 so as to give an idea of the real scores over a five-point scale. Of the three opportunity variables - promotion, development, and recognition - on a five-point scale where $1=$ strongly disagree and $5=$ strongly agree, employees perceive that they mostly have development opportunity (3.33), followed by recognition opportunity (3.05); both of which are above the mid-point of the scale. The opportunity that employees perceive they have the least is promotion (2.49). Thus, on average, respondents are slightly more inclined to state that they do not have promotion opportunity. Of the four leadership variables - paternalistic, transactional, transformational, and participative leadership - employees perceive that their managers primarily have paternalistic leadership attributes (3.76), followed by transformational leadership (3.50) and participative leadership attributes (3.43). Employees perceive that their managers have transactional leadership attributes (3.31) the least. In all leadership variables, respondents are more inclined to agree that their managers' leadership styles are transactional, transformational, and participative, but especially paternalistic. Employees, on average, are more inclined to agree that their organizations carry out HPWPs (3.40). T-tests were carried out to 
understand if there are any statistically significant differences in mean scores of employees working in manufacturing industry and those working in other (i.e. service, export-import, and retail) industries. Results of t-tests show that there are no industry-related differences in mean scores except for the variables of recognition opportunity and participative leadership. Recognition opportunity is higher $(p<.05)$ for employees working in manufacturing (3.09) than the ones in non-manufacturing industries (2.85). Similarly, the level of perceived participative leadership is higher $(p<.01)$ in employees in manufacturing (3.48) than the ones in non-manufacturing industries (3.19).

All independent variables are significantly correlated with development opportunity. HPWPs, paternalistic and participative leadership are significantly correlated with recognition opportunity. HPWPs, transactional and participative leadership are significantly correlated with promotion opportunity. The Cronbach's alpha values range from .74 to .92 and are esteemed high since they are above .70 (Hair et al., 1998).

\subsection{Factor Analyses}

Kaiser-Meyer-Olkin (KMO) measure of sampling adequacy figures indicate the suitability of the data for factor analyses. A KMO measure of sampling adequacy of above 0.60 is tolerable, while higher values are desired (Sharma, 1996); the KMO measure of sampling adequacy was 0.70 or above for all of the study variables. Thus, the data were suitable for factor analyses. Factor analyses were carried out using principal component analysis. In all cases, some items loaded to more than one factor in all cases and Varimax rotation was carried out. Items relating to opportunity variables loaded to three factors instead of the four expected. Items on promotion opportunity loaded to one factor which was called "promotion opportunity," and items on recognition opportunity loaded to one factor which was called "recognition opportunity." All items on development opportunity and all items on continual challenge loaded to one factor which was called "development opportunity" (so named for simplicity since continual challenge can be considered a development opportunity as well). In terms of variance, $73 \%$ was explained in relation to opportunity dimensions. In the case of leadership items, items on paternalistic, transactional, transformational, and participative leadership loaded to one factor each, as expected, and the variance explained was $81 \%$. Items on HPWPs loaded to one factor, as expected, and $56 \%$ of the variance was explained. Hair et al. (1998: 104) stated that, in the social sciences "it is not uncommon to consider a solution that accounts for $60 \%$ of the variance (and in some instances even less) as satisfactory"; thus, following Hair et al. (1998), all total variance explained figures are considered satisfactory. Opportunity items loaded with at least .56; leadership items loaded with at least .60; and HPWP items loaded with at least .71. A factor loading of .50 is significant for a sample size of 120 and over (Hair et al., 1998). Thus, the factor loadings of all items are significant. To avoid complications that might be caused by multicollinearity, researchers are advised to use factor scores of independent variables in regression analyses (Hair et al., 1998). Hence, factor scores of HPWPs and leadership dimensions were calculated and used in the regression analyses.

\subsection{Results of the Hypotheses Tests}

To test the hypotheses, the relationships between independent variables (e.g. HPWPs and leadership variables) and opportunity variables were tested using two-step hierarchical regression analyses (Cohen et al., 2003), controlling for age, gender, education, socioeconomic status, and tenure. In factor analysis, items on both development opportunity and continual challenge loaded to one factor, "development opportunity," and entered the regression analyses as a single construct. Therefore, the results for the hypotheses on development opportunity and continual challenge were combined in the results of the hypotheses tests.

Three analyses carried out. The control variables were entered into the equation first (Model 1 in Table 3), followed by the variables relating to HPWPs and leadership (Model 2 in Table 3). Hair et al. (1998) states that no condition index should be greater than 30, and no VIF value should be greater than 10 to be able to eliminate the possibility of multicollinearity. In the analyses, the largest condition index value was 16.14 while the largest VIF value was 2.13. Thus, multicollinearity was not a problem. The results are shown in Table 3. 
Table 3. Results of Hierarchical Regression Analyses Predicting Promotion, Development, and Recognition Opportunities $^{\mathrm{a}, \mathrm{b}}$

\begin{tabular}{|c|c|c|c|c|c|c|}
\hline & \multicolumn{2}{|c|}{ Promotion opportunity } & \multicolumn{2}{|c|}{ Development opportunity } & \multicolumn{2}{|c|}{ Recognition opportunity } \\
\hline & Model 1 & Model 2 & Model 1 & Model 2 & Model 1 & Model 2 \\
\hline Age & .11 & .11 & -.07 & -.10 & .01 & -.02 \\
\hline Gender $^{a}$ & $-.11 *$ & $-.09 *$ & -.05 & -.01 & -.04 & -.03 \\
\hline Education & $.14^{* *}$ & $.13^{* *}$ & $.13^{* *}$ & .05 & $.15^{* *}$ & $.11^{*}$ \\
\hline $\begin{array}{l}\text { Socioeconomic } \\
\text { status }\end{array}$ & $.13^{* *}$ & $.13^{* *}$ & .04 & -.02 & -.03 & -.06 \\
\hline Tenure & $.00^{\mathrm{b}}$ & -.01 & -.03 & .03 & $.16^{*}$ & $.19 * *$ \\
\hline HPWPs & & $.14^{*}$ & & $.22 * * *$ & & .11 \\
\hline $\begin{array}{l}\text { Paternalistic } \\
\text { leadership }\end{array}$ & & $-.15^{* *}$ & & $.10^{*}$ & & .08 \\
\hline $\begin{array}{l}\text { Transactional } \\
\text { leadership }\end{array}$ & & $.18 * * *$ & & $.13^{* * *}$ & & .03 \\
\hline $\begin{array}{l}\text { Transformational } \\
\text { leadership }\end{array}$ & & .04 & & $.24 * * *$ & & .04 \\
\hline $\begin{array}{l}\text { Participative } \\
\text { leadership }\end{array}$ & & .06 & & $.34 * * *$ & & $.19 * * *$ \\
\hline$\Delta \mathrm{R}^{2}$ & & $.09 * * *$ & & $.35 * * *$ & & $.08 * * *$ \\
\hline$R^{2}$ & $.08 * * *$ & $.16^{* * *}$ & $.03 * *$ & $.38 * * *$ & $.04^{* *}$ & $.12 * * *$ \\
\hline Adjusted $\mathrm{R}^{2}$ & $.07 * * *$ & $.14^{* * *}$ & $.02 * *$ & $.37^{* * *}$ & $.03 * *$ & $.10 * * *$ \\
\hline$F$ & $7.775^{* * *}$ & $8.900 * * *$ & $3.123 * * *$ & $28.261^{* * *}$ & $3.796 * * *$ & $6.238 * * *$ \\
\hline
\end{tabular}

Note. Standardized regression coefficients are reported for a two-tailed test. $N=550$.

a $0=$ male, $1=$ female.

b The value shown as .00 is less than .005 .

${ }^{*} p<.05, * * p<.01, * * * p<.001$

Hypothesis 1 proposes that HPWPs are positively related to a) promotion, b) development, c) continual challenge, and d) recognition opportunities. As shown in Table 3 , the regression results indicate that HPWPs predict promotion $(\beta=.14, p<.05)$ and development opportunity $(\beta=.22, p<.001)$ in a significant way, after controlling for age, gender, education, economic status, and tenure. Hence, Hypotheses $1 \mathrm{a}$ and $1 b \& c$ are supported. However, HPWPs fail to predict recognition opportunity. Thus, Hypothesis $1 d$ is not supported, based on the results of the regression analysis. The findings show that employees receive more promotion and development opportunities as their experiences of HPWPs increase.

Hypothesis 2 proposes that paternalistic leadership is positively related to a) promotion, b) development, c) continual challenge, and d) recognition opportunities. . Paternalistic leadership is negatively related to promotion opportunity $(\beta=-.15, p<.01)$. Thus, Hypothesis $2 a$ is not supported. Paternalistic leadership predicts development opportunity $(\beta=.10, p<.05)$, giving support for Hypotheses $2 b \& c$. However, paternalistic leadership does not predict recognition opportunity, hence, Hypothesis $2 d$ is not supported. The findings show that employees receive more development opportunities as their experiences of paternalistic leadership increase, and receive fewer promotion opportunities as their leaders exercise more paternalistic leadership.

Hypothesis 3 proposes that transactional leadership is positively related to a) promotion, b) development, c) continual challenge, and d) recognition opportunities. Transactional leadership predicts promotion opportunity $(\beta=.18, p<.001)$ and development opportunity $(\beta=.13, p<.001)$, as seen in Table 3 . Hence, Hypotheses $3 a$ and $3 b \& c$ are supported. However, transactional leadership does not predict recognition opportunity; hence, Hypothesis $3 d$ is not supported. The findings show that employees receive more promotion and development opportunities as their experiences of transactional leadership increase. 
Hypothesis 4 proposes that transformational leadership is positively related to a) promotion, b) development, c) continual challenge, and d) recognition opportunities. The results show that transformational leadership does not predict promotion opportunity and recognition opportunity, as shown in Table 3; hence, Hypotheses $4 \mathrm{a}$ and $4 \mathrm{~d}$ are not supported. However, transformational leadership does predict development opportunity $(\beta=.24, p<.001)$; hence, Hypotheses $4 b \& c$ are supported. The findings show that employees receive more development opportunities as their experiences of transformational leadership increase.

Hypothesis 5 proposes that participative leadership is positively related to a) development, b) continual challenge, and $c$ ) recognition opportunities. As shown in Table 3, participative leadership predicts development opportunity $(\beta=.34, p<.001)$ and recognition opportunity $(\beta=.19, p<.001)$. Hence, Hypotheses $5 a \& b$ and $4 c$ are supported. The findings show that employees receive more development and recognition opportunities as their experiences of participative leadership increase.

Results of hypotheses are shown in Table 4.

Table 4. Results of the Hypotheses

\begin{tabular}{lll}
\hline Hypothesis 1a & HPWPs are positively related to promotion opportunity. & $\mathrm{S}$ \\
Hypothesis 1b & HPWPs are positively related to development opportunity. & $\mathrm{S}$ \\
Hypothesis 1c & HPWPs are positively related to continual challenge. & $\mathrm{S}$ \\
Hypothesis 1d & HPWPs are positively related to recognition opportunity. & NS \\
\hline Hypothesis 2a & Paternalistic leadership is positively related to promotion opportunity. & $\mathrm{S}$ \\
Hypothesis 2b & Paternalistic leadership is positively related to development opportunity. & $\mathrm{S}$ \\
Hypothesis 2c & Paternalistic leadership is positively related to continual challenge. & NS \\
Hypothesis 2d & Paternalistic leadership is positively related to recognition opportunity. & $\mathrm{S}$ \\
\hline Hypothesis 3a & Transactional leadership is positively related to promotion opportunity. & $\mathrm{S}$ \\
Hypothesis 3b & Transactional leadership is positively related to development opportunity. & $\mathrm{S}$ \\
Hypothesis 3c & Transactional leadership is positively related to continual challenge. & $\mathrm{NS}$ \\
Hypothesis 3d & Transactional leadership is positively related to recognition opportunity. & NS \\
\hline Hypothesis 4a & Transformational leadership is positively related to promotion opportunity. \\
Hypothesis 4b & Transformational leadership is positively related to development opportunity. & $\mathrm{S}$ \\
Hypothesis 4c & Transformational leadership is positively related to continual challenge. & $\mathrm{S}$ \\
Hypothesis 4d & Transformational leadership is positively related to recognition opportunity. & NS \\
\hline Hypothesis 5a & Participative leadership is positively related to development opportunity. & $\mathrm{S}$ \\
Hypothesis 5b & Participative leadership is positively related to continual challenge. & $\mathrm{S}$ \\
Hypothesis 5c & Participative leadership is positively related to recognition opportunity. & $\mathrm{S}$ \\
\hline \hline
\end{tabular}

S= Supported, NS= Not supported

When the data is analyzed separately for employees working in manufacturing and nonmanufacturing (i.e. service, export-import, and retail) industries, most of the results were the same with a few diversions. HPWPs are unrelated not only to promotion opportunity for employees working in manufacturing industry ( $p>20)$, but also to development opportunity for employees working in nonmanufacturing industries $(p>.70)$. Moreover, paternalistic leadership is not related to development opportunity for employees working in both manufacturing $(p>.05)$ and non-manufacturing industries $(p>.50)$, which is interesting because it is related when the whole sample rather than separate samples is considered. 


\section{Discussion and Conclusions}

Opportunity is vital for both employees and employers. As discussed by Kanter (1977), it is a "major" antecedent of many organizational outcomes. Moreover, opportunity is a positive phenomenon in itself. However, although opportunity is a significant topic of research, the concept of opportunity and its antecedents have not previously been fully explored. To fill this gap in the research, this study aimed to explore opportunity and analyze the possible antecedents of opportunity.

Different types of work opportunities are identified from the literature review. Using data obtained from 550 white-collar employees in Turkey, factor analyses result in opportunity being explained by three factors: promotion, development, and recognition opportunities. Regression analyses were carried out in order to test the hypotheses.

\subsection{Theoretical Implications}

A significant finding of the study is that transactional, transformational, and participative leadership create opportunity for employees. All three types of leadership are related to development opportunity, while transactional leadership is associated with promotion opportunity, and participative leadership predicts recognition opportunity. Thus, overall, these three types of leadership create one type of opportunity or other.

Paternalistic leadership increases development opportunity with a smaller power compared to other types of leadership $(\beta=.10, p<.05)$ when the whole sample is considered. However, when the data is analyzed separately for employees working in manufacturing and non-manufacturing (i.e. service, export-import, and retail) industries, paternalistic leadership is unrelated to development opportunity for both groups. Moreover, results of analyses show that paternalistic leadership reduces promotion opportunity. As discussed previously, paternalism might be both negatively (Lee, 2001) and positively (Aycan, 2001; Lee, 2001) related to the opportunity perceptions of employees. Paternalism might have a negative effect on opportunity since, in many paternalistic systems, there is no systematic scientific procedure for the evaluation of individuals' skills, abilities, and job performance. Instead, there is managerial autonomy in hiring, staffing, and training (Lee, 2001). Paternalism may have a positive effect since paternal figures consider employees and take their rights and feelings into account, and provide support and protection to those under their care (Aycan, 2001; Lee, 2001). Since paternalistic leadership is perceived more positively in paternalistic cultures like Turkey (Aycan, 2001; Kabasakal \& Bodur, 2002; Fikret-Pasa et al., 2001, Dilber, 1967), it was estimated that this style would be positively related to the perceived level of opportunity. However, the results show that paternalistic leadership is negatively related to promotion opportunity. The negative relationship with promotion opportunity is in parallel with the negative literature on paternalism. Moreover, the inherent father-/mother-child relationship in paternalism may result in viewing employees as children, thereby failing to increase their positions or statuses, and taking care of them and supporting them as children.

The results also show that HPWPs increase promotion and development opportunities for employees. However, when the data is analyzed separately for employees working in manufacturing and non-manufacturing industries, HPWPs do not predict promotion opportunity for manufacturing employees and development opportunity for non-manufacturing employees.

When the mean scores of variables for employees in different industries are compared, the results show that recognition opportunity and the level of perceived participative leadership is higher in employees in manufacturing than the ones in non-manufacturing industries.

An examination of the results also shows that some variables can be explained more easily than others. The type of opportunity with the highest variance explained is development, followed by promotion. The type of opportunity with the lowest variance explained is recognition. 


\subsection{Managerial Implications}

A significant finding of the study is that transactional, transformational, and participative leadership create opportunity for employees. However, paternalistic leadership is not related to recognition opportunity. In addition, it is not related to development opportunity when the data is analyzed separately for employees working in manufacturing and non-manufacturing industries. Moreover, it is negatively related to promotion opportunity. Thus, executives are recommended to hire or train managers to use the characteristics of transactional, transformational, and participative leadership and not paternalistic leadership in order to increase opportunity for employees.

To increase opportunity, managers are advised to be transactional leaders, and clarify rewards that employees can achieve based on their work, effort, and success; reward achievements of employees; and make sure the employees get the credit when they accomplish something substantial at work. To enhance opportunity, managers are also recommended to be transformational leaders, and encourage employees to improve their job-related skills and abilities; coach them to improve their performance when they need it, and work to get them to develop to their full potential. To increase opportunity, managers are also advised to be participative leaders, and encourage employees to express their ideas and suggestions; use their suggestions to make decisions that affect them, and consider their ideas when one disagrees with them. Whatever course of action the managers choose to follow based on the recommendations, they will be creating at least one type of opportunity for their employees.

The results also show that HPWPs increase promotion and development opportunities. However, when the data is analyzed separately for employees working in manufacturing and non-manufacturing industries, HPWPs are unrelated to promotion opportunity for manufacturing employees, and to development opportunity for non-manufacturing employees. However, HPWPs predict development opportunity for manufacturing and promotion opportunity for non-manufacturing employees. Thus, company executives are recommended to hire new employees with care, retain employees when their jobs are eliminated, promote employees from within the company, instead of filling positions with outside candidates, whenever possible, and support the growth and development of employees.

Nevertheless, the three leadership types of transactional, transformational, and participative leadership are much more influential than HPWPs in increasing opportunity at work for employees. Hence, executives are advised to give priority to the recommendation on hiring or training managers to use the characteristics of transactional, transformational, and participative leadership.

\subsection{Limitations and Suggestions for Future Research}

The study has some limitations. First, the study was carried out in Turkey, and it may be inappropriate to generalize the results to employees working in other geographical locations. Thus, the hypotheses should be tested in other contexts to achieve the generalizability of the results.

Second, leadership types that have positive effects were studied. Leadership types such as authoritarian leadership (Vroom \& Mann, 1960) may have negative effects on opportunity at work, and should be explored in future research.

Third, since self-reported surveys were used, there was potential for common method bias (Podsakoff et al., 2003). To minimize this, several things were done. Firstly, the questionnaire was pretested with a sample of 10 white-collar employees and a pilot study was carried out to further clarify the questions using a sample of 102 white-collar employees to minimize item ambiguity (Podsakoff et al., 2003). Secondly, the items on dependent variables were placed before the items on independent variables in the questionnaire to eliminate priming effects (Podsakoff \& Organ, 1986) based on the arguments set forth by Salancik and Pfeffer $(1977,1978)$. Thirdly, Harman's single-factor test was carried out using the procedure suggested by Podsakoff et al. (2003). The factor analysis did not produce a single factor, but rather five factors; this accounted for $72 \%$ of the variance, with the first factor accounting for $35 \%$ of the total, rather than the majority of the covariance among the measures, thus passing Harman's test. However, the 
hypotheses should be tested using data from multiple sources in the future, in order to eliminate any possibility of common method bias.

Nevertheless, the study makes vital contributions to the literature. It fills a gap in the research by exploring the concept of opportunity - which is important for both employees and employers - in depth; determining its dimensions; and examining its antecedents, providing important implications for both research and practice, and suggestions for future research.

\section{References}

Ali, N., Babar, M. A. A., \& Bangash, S. A. (2011). Relationship between leadership styles and organizational commitment amongst medical representatives of national and multinational pharmaceuticals companies, Pakistan (an empirical study). Interdisciplinary Journal of Contemporary Research in Business, 2(10), 524-529.

Allen, T. D., Poteet, M. L., \& Russell, J. E. A. (1998). Attitudes of managers who are more or less career plateaued. The Career Development Quarterly, 47(2), 159-172.

Appelbaum, E., Bailey, T, Berg, P., \& Kalleberg, A.L. (2000). Manufacturing advantage: Why high-performance work systems pay off. Ithaca, NY: Cornell University Press.

Appelbaum, S. H., \& Kamal, R. (2000). An analysis of the utilization and effectiveness of non-financial incentives in small business. The Journal of Management Development, 19(9/10), 733-763.

Arnold, J. A., Arad, S., Rhoades, J. A., \& Drasgow, F. (2000). The empowering leadership questionnaire: The construction and validation of a new scale for measuring leader behaviors. Journal of Organizational Behavior, 21(3), 249269.

Arthur, J. (1992). The link between business strategy and industrial relations systems in American steel minimills. Industrial and Labor Relations Review, 45(3), 488-506.

Avolio, B. J., \& Bass, B. M. (Eds.). (2001). Developing potential across a full range of leadership TM: Cases on transactional and transformational leadership. Mahwah, NJ: Lawrence Erlbaum Associates, Inc.

Avolio, B. J., Bass, B. M., \& Jung, D. I. (1999). Re-examining the components of transformational and transactional leadership using the multifactor leadership questionnaire. Journal of Occupational and Organizational Psychology, 72(4), 441-462.

Aycan, Z. (2001). Human resource management in Turkey - Current issues and future challenges. International Journal of Manpower, 22(3), 252-260.

Aycan, Z. (2006). Paternalism: Towards conceptual refinement and operationalization. In K. S. Yang, K. K. Hwang, \& U. Kim (Eds.), Scientific advances in indigenous psychologies: Empirical, philosophical, and cultural contributions, (pp. 445-466). London: Cambridge University Press.

Baron, J. N., Davis-Blake, A., \& Bielby, W. T. (1986). The structure of opportunity: How promotion ladders vary within and among organizations. Administrative Science Quarterly, 31(2), 248-273.

Bass, B. M. (1992). Stress and leadership. In F. Heller (Ed.), Decision-making and leadership (pp. 133-155). Cambridge, UK: Cambridge University Press.

Bass, B. M. (1999). Two decades of research and development in transformational leadership. European Journal of Work and Organizational Psychology, 8(1), 9-32.

Birdi, K. S., Patterson, M. G., \& Wood, S. J. (2012). Learning to perform? A comparison of learning practices and organizational performance in profit- and non-profit-making sectors in the UK. International Journal of Training and Development, 11(4), 265-281.

Bono, J. E., \& Judge, T. A. (2004). Personality and transformational and transactional leadership: A meta-analysis. Journal of Applied Psychology, 89(5), 901-910.

Cameron, K. S., Dutton, J. E., \& Quinn, R. E. (2003). An introduction to positive organizational scholarship. In K. S. Cameron, J. E. Dutton, \& R. E. Quinn (Eds.), Positive organizational scholarship (pp. 3-13). San Francisco, CA: Berrett-Koehler.

Carmeli, A. (2005). The relationship between organizational culture and withdrawal intentions and behaviour. International Journal of Manpower, 26(2), 177-207. 
Cassirer, N., \& Reskin, B. (2000). High hopes: Organizational position, employment experiences, and women's and men's promotion aspirations. Work and Occupations, 27(4), 438-464.

Caudron, S. (1994). HR revamps career itineraries. Personnel Journal, 73(4), 64A-64P.

Chew, J., \& Chan, C. C. A. (2008). Human resource practices, organizational commitment and intention to stay. International Journal of Manpower, 29(6), 503 - 522.

Cohen, J., Cohen, P., West, S. G., \& Aiken, L. S. (2003). Applied multiple regression/correlation analysis for the behavioral sciences (3rd ed.). Mahwah, NJ: Lawrence Erlbaum Associates.

Colarelli, S. M., Dean, R. A., \& Konstans, C. (1987). Comparative effects of personal and situational influences on job outcomes of new professionals. Journal of Applied Psychology, 72(4), 558-566.

Combs, J., Liu, Y., Hall, A., \& Ketchen, D. (2006). How much do high-performance work practices matter? A meta-analysis of their effects on organizational performance. Personnel Psychology, 59(3), 501-528.

Delery, J., \& Doty, D. H. (1996). Modes of theorizing in strategic human resource management: tests of universalistic, contingency, and configurational performance predictions. Academy of Management Journal, 39(4), 802-35.

Dilber, M. (1967). Management in the Turkish private sector industry. Ann Arbor, MI: University Microfilms Inc.

Dutton, J., Glynn, M. A., \& Spreitzer, G. (2006). Positive organizational scholarship. In J. Greenhaus \& G. Callahan (Eds.), Encyclopedia of career development, Vol. 2 (pp. 641-644). Thousand Oaks, CA: Sage.

Eliyana, A. (2010). Impacts of transactional and transformational leaderships upon organizational citizenship behaviour. Journal of US-China Public Administration, 7(6), 24-30.

Feldman, D. C. (1996). Managing careers in downsizing firms. Human Resource Management, 35(2), $145-161$.

Fikret-Pasa, S., Kabasakal, H., \& Bodur, M. (2001). Society, organizations, and leadership in Turkey. Applied Psychology, 50(4), pp. 559-589.

Fleming, P. (2005). 'Kindergarten cop': Paternalism and resistance in a high-commitment workplace. Journal of Management Studies, 42(7), 1469-1489.

Ganesan, S., \& Weitz, B. A. (1996). The impact of staffing policies on retail buyer job attitudes and behaviors. Journal of Retailing, 72(1), 31-56.

Gharibvand, S. (2012). The relationship between Malaysian organizational culture, participative leadership style, and employee job satisfaction among Malaysian employees from semiconductor industry. International Journal of Business and Social Science, 3(16), 289-298.

Greenhaus, J. H., Parasuraman, S., \& Wormley, W. M. (1990). Effects of race on organizational experiences, job performance evaluations, and career outcomes. Academy of Management Journal, 33(1), 64-86.

Hair, J. F. Jr., Anderson, R. E., Tatham, R. L., \& Black, W. C. (1998). Multivariate data analysis (5th ed.). Upper Saddle River, NJ: Prentice Hall International.

Harlan, S. L. (1989). Opportunity and attitudes toward job advancement in a manufacturing firm. Social Forces, 67(3), 766-788.

Hartog, D. N. D., Van Muijen, J. J., \& Koopman, P. L. (1997). Transactional versus transformational leadership: An analysis of the MLQ. Journal of Occupational \& Organizational Psychology, 70(1), 19-34.

House, R. J. (1996). Path-goal theory of leadership: Lessons, legacy, and a reformulated theory. The Leadership Quarterly, 7(3), 323-352.

House, R. J., \& Mitchell, T. R. (1974). Path-goal theory of leadership. Contemporary Business, 3(4), 81-98.

Howell, J. M., \& Hall-Merenda, K. E. (1999). The ties that bind: the impact of leader-member exchange, transformational and transactional leadership, and distance on predicting follower performance. Journal of Applied Psychology, 84(5), 680-694.

Huang, T. M. (2011). The relationship between headmasters' leadership behaviour and teachers commitment in primary schools in the district of Sarikei, Sarawak. Procedia - Social and Behavioral Sciences, 29(1), 1725-1732.

Huang, X., Shi, K, Zhang, Z., \& Cheung, Y. L. (2006). The impact of participative leadership behavior on psychological empowerment and organizational commitment in Chinese state-owned enterprises: the moderating role of organizational tenure. Asia Pacific Journal of Management, 23(3), 345-367.

Huselid, M. (1995). The impact of human resource management practices on turnover, productivity, and corporate financial performance. Academy of Management Journal, 38(3), 635-672. 
Igbaria, M., \& Baroudi, J. J. (1995). The impact of job performance evaluations on career advancement prospects: An examination of gender differences in the IS workplace. MIS Quarterly, 19(1), 107-123.

lles, P. (1997). Sustainable high-potential career development: A resource-based view. Career Development International, 2(7), 347-353.

Ismail, A., Mohamed, H. A.-B., Sulaiman, A. Z., Mohamad, M. H., \& Yusuf, M. H. (2011). An empirical study of the relationship between transformational leadership, empowerment and organizational commitment. Business and Economics Research Journal, 2(1): 89-107.

Kabasakal, H., \& Bodur, M. (2002). Arabic cluster: A bridge between East and West. Journal of World Business, 37(1), 40-54.

Kalleberg, A. L., \& Van Buren, M. E. (1996). Is bigger better? Explaining the relationship between organization size and job rewards. American Sociological Review, 61(1), 47-66.

Kanter, R. M. (1977). Men and women of the corporation. New York: Basic Books.

Kanter, R. M. (1986). Holiday gifts: Celebrating employee achievements. Management Review, 75(12), $19-21$.

Kanter, R. M., \& Stein B. A. (1981). Ungluing the stuck: Motivating performance and productivity through expanding opportunity. Management Review, 70(7), 45-49.

Kim, S.-W., Price, J. L, Mueller, C. W., \& Watson, T. W. (1996). The determinants of career intent among physicians at a U.S. Air Force hospital. Human Relations, 49(7), 947-976.

Landau, J., \& Hammer, T. H. (1986). Clerical employees' perceptions of intraorganizational career opportunities. Academy of Management Journal, 29(2), 385-404.

Lee, H.-S. (2001). Paternalistic human resource practices: their emergence and characteristics. Journal of Economic Issues, 35(4), 841-869.

Mano-Negrin, R., \& Tzafrir, S. S. (2004). Job search modes and turnover. Career Development International, 9(5), 442 458.

Noe, R. A., Steffy, B. D., \& Barber, A. E. (1988). An investigation of the factors influencing employees' willingness to accept mobility opportunities. Personnel Psychology, 41(3), 559-580.

Obiwuru, T. C., Okwu, A. T., \& Akpa, V. O. (2011). Effects of leadership style on organizational performance: a survey of selected small scale enterprises in Ikosi-Ketu council development area of Lagos State, Nigeria. Australian Journal of Business and Management Research, 1(7), 100-111.

Pellegrini, E. K., Scandura, T. A., \& Jayaraman, V. (2010). Cross-cultural generalizability of paternalistic leadership: An expansion of leader-member exchange theory. Group \& Organization Management, 35(4), 391-420.

Podsakoff, P. M., MacKenzie, S. B., Lee, J. Y., \& Podsakoff, N. P. (2003). Common method biases in behavioural research: a critical review of the literature and recommended remedies. Journal of Applied Psychology, 88(5), 879-903.

Podsakoff, P. M., \& Organ, D. W. (1986). Self-reports in organizational research: Problems and prospects. Journal of Management, 12(4), 531-544.

Prince, J. B. (2005). Career-focused employee transfer processes. Career Development International, 10(4), $293-340$.

Rafferty, A. E., \& Griffin, M. A. (2006). Refining individualized consideration: distinguishing developmental leadership and supportive leadership. Journal of Occupational and Organizational Psychology, 79(1), 37-61.

Rowold, J., \& Heinitz, K. (2007). Transformational and charismatic leadership: Assessing the convergent, divergent and criterion validity of the MLQ and the CKS. The Leadership Quarterly, 18(2), 121-133.

Salancik, G. R., \& Pfeffer, J. (1977). An examination of the need-satisfaction models of job attitudes. Administrative Science Quarterly, 22(3), 427-456.

Salancik, G. R., \& Pfeffer J. (1978). A social information processing approach to job attitudes. Administrative Science Quarterly, 23(2), 224-253.

Sharma, S. (1996). Applied multivariate techniques. NY, USA: John Wiley \& Sons, Inc.

Somech, A., \& Wenderow, M. (2006). The impact of participative and directive leadership on teachers' performance: the intervening effects of job structuring, decision domain, and leader-member exchange. Educational Administration Quarterly, 42(5), 746-772.

Tachibanaki, T. (1987). The determination of the promotion process in organizations and of earnings differentials. Journal of Economic Behavior \& Organization, 8(4), 603-616. 
Taylor, S., Levy, O., Boyacigiller, N., \& Beechler, S. (2008). Employee commitment in MNCs: Impacts of organizational culture, HRM and top management orientations. The International Journal of Human Resource Management, 19(4), 501-527.

Vroom, V. H., \& Mann, F C. (1960). Leader authoritarianism and employee attitudes. Personnel Psychology, 13(2), 125140.

Wayne, S. J., Shore, L. M., Bommer, W. H., \& Tetrick L. E. (2002). The role of fair treatment and rewards in perceptions of organizational support and leader-member exchange. Journal of Applied Psychology, 87(3), 590-598.

Yang, S., Worden, S., \& Wilson, G. (2004). Sources of organizational commitment: The effects of internal labor markets and worker values. Sociological Spectrum, 24(6), 667-688.

Yukl, G. (2002). Leadership in organizations (5th ed.). Upper Saddle River, NJ: Prentice-Hall.

Zhao, J. J, Truell, A. D., Alexander, M. W., \& Hill, I. B. (2006). Less success than meets the eye? The impact of Master of Business Administration education on graduates' careers. Journal of Education for Business, 81(5), 261-268. 


\section{Appendix: Questionnaire Items}

Unless otherwise stated, the response format for measures used a range from 1 (strongly disagree) to 5 (strongly agree).

\section{Promotion Opportunity}

1) What is the likelihood that you will be promoted to a higher position with your present employer in the next five years? (Kalleberg \& Van Buren, 1996)

( 1 = no likelihood, 2 = low likelihood, 3 = moderate likelihood, 4 = high likelihood, 5 = certain/no doubt).

2) How would you rate your chances for promotion to a higher position sometime during your career with this company? (Greenhaus et al., 1990; Igbaria \& Baroudi, 1995)

( $1=$ no chance, 2 = low chance, $3=$ moderate chance, $4=$ good chance, $5=$ very good chance) .

3) Please indicate the degree to which you agree with the following statement:

This company has many promotion opportunities for me (Ganesan \& Weitz, 1996).

\section{Development Opportunity}

Please indicate to what degree you agree with the following statements:

1) The company I work for provides the opportunity for me to keep up with new developments related to my job (Kim et al., 1996).

2) I have sufficient opportunity to develop new skills and abilities in the company for which I work (Noe et al., 1988).

3) My job gives me the chance to learn new things (Prince, 2005).

4) My job requires me to do many different things at work, using a variety of skills and talents (Carmeli, 2005).

5) In my present company, I have the chance to do a different job or work in a different department where I can learn new things (new item).

6) My job may get bigger through new responsibilities in the future (new item).

\section{Recognition Opportunity}

Please compare yourself with your colleagues at about the same level in the company at which you work and indicate the degree to which you have the following opportunities, compared to them:

( $1=$ much less, 2 = less, $3=$ same level, $4=$ more, $5=$ much more)

1) Visibility to upper management (Wayne et al., 2002).

2) Personal attention from upper management (Wayne et al., 2002).

3) Recognition from upper management (Wayne et al., 2002).

\section{High Performance Work Practices}

Please indicate the degree to which you agree with the following statements:

1) This organization hires new employees with care (Huselid, 1995; Taylor et al., 2008).

2) This organization tries to retain - rather than release - employees when their jobs are eliminated (Delery \& Doty, 1996; Taylor et al., 2008).

3) Whenever possible, this organization promotes employees from within the company, rather than filling positions with outside candidates (Huselid, 1995; Taylor et al., 2008). 
4) In this organization, there is support for the growth and development of employees (Delery \& Doty, 1996; Taylor et al., 2008).

\section{Paternalistic Leadership}

Please indicate the degree to which you agree with the following statements:

1) My manager treats his/her employees as if he/she were a family member (father/mother or elder brother/sister) (Aycan, 2006).

2) My manager expects attachment and loyalty from his/her employees in return for his/her care and involvement (Aycan, 2006).

3) My manager wants to have full control over and be fully informed about all issues related to work (Aycan, 2006).

\section{Transactional Leadership (the dimension of contingent rewarding)}

Please indicate the degree to which you agree with the following statements:

1) My manager clarifies rewards (that we can achieve based on our work, effort, and success) (Avolio et al., 1999).

2) My manager rewards my achievements (Avolio et al., 1999).

3) My manager makes sure I get the credit when I accomplish something substantial on the job (Greenhaus et al., 1990).

\section{Transformational Leadership (the dimension of individualized consideration)}

Please indicate the degree to which you agree with the following statements:

1) My manager encourages me to improve my job-related skills and abilities (Rafferty \& Griffin, 2006).

2) My manager coaches me to improve my performance when I need it (Rafferty \& Griffin, 2006).

3) My manager works to get me to develop to my full potential (Avolio et al., 1999).

\section{Participative Leadership}

Please indicate the degree to which you agree with the following statements:

1) My manager encourages us to express ideas/suggestions (Arnold et al., 2000; Huang et al., 2006).

2) My manager uses our suggestions to make decisions that affect us (Arnold et al., 2000; Huang et al., 2006).

3) My manager considers our ideas when he/she disagrees with us (Arnold et al., 2000; Huang et al., 2006). 